\title{
Linking Green Human Resource Management Bundle to Environmental Performance in Malaysia's Hotel Industry:The Mediating Role of Organizational Citizenship Behaviour Towards Environment
}

\author{
Yusmani Mohd Yusoff
}

\begin{abstract}
Recently, many businesses are transforming themselves from a conventional financial perspective to a competency based; strategic perspective. Sustainability is one of the main strategy aspects of present corporate world. Environmental issues have already been widespread as one of the main components of the business sustainability. Hence, numerous organizations in most of the industries are implementing a proactive and strategic environmental performance programs to gain competitive advantage such as green human resource management (GHRM). However, investment in GHRM practices will have not only a direct effect on environmental performance, but also an indirect effect through several mediating variables because of the nature underlying the green HRM practices concept. Studies in GHRM literature has paid scarce attention to the identification of preceding organizational capabilities that could inspire the adoption of environmental performance programs. Grounded by hotel industry in Malaysia as the hotel industry is one of the sectors which largely contribute to the environmental issues. This study utilized a research model to determine how the GHRM bundle through organizational citizenship behaviour towards environment (OCBE) will help to enhance the environmental performance in Malaysia's hotel industry.
\end{abstract}

Keywords : Green Human Resource Management Bundle Practices; Organizational Citizenship towards Environment; Environmental Performance; Hotel Industry

\section{INTRODUCTION}

Organizations that implement the concept of green business such as green human resource management (GHRM) will reach greater financial savings that produce profits. Green business such as GHRM and green supply chain can help the organization to enhance their performance especially environmental performance and achieve green corporate culture. GHRM practices become one of the green business significant programs because this program refers to the effort of the organization in transforming normal employees into green employees

Revised Manuscript Received on July 22, 2019.

Yusmani Mohd Yusoff

School of Business Management, Universiti Utara Malaysia (UUM), Malaysia (employees that engage in pro-environmental behaviours) (Zientara \& Zamojska, 2016) by all the activities involved in the development, implementation and on-going maintenance of a system, hence, finally to create a significant impact on environmental sustainability (Opatha \& Arulrajah, 2014). GHRM practices involve capable, talented, and motivated employees to execute the organization's environmental performance programs (Brammer, Millington, \& Rayton, 2007). GHRM practices are the best approach helps organizations to implement the environmental performance programs by forming green employees that can appreciate and identify the environmental issues in business activities by concentrating on green recruitment and selection; green training and development; green performance management and appraisal; and green pay and reward system and improving the organization's human capital (Dutta, 2012). However, Combs, Liu, Hall and Ketchen (2006) emphasized that conventional human resource management (HRM) has focused widely on individual practice instead of a set of practice. Therefore, instead of study individual GHRM practices such as green recruitment and selection; green training and development; green performance and many more, this study focuses on GHRM bundle practices. Alfes, Shantz, Truss and Soane (2013) suggested that association of interconnected elements inside GHRM practices is internally dependable.

Environmental performance has become gradually crucial for organizations such as hotel industry as they are pressured by many stakeholders such as society, competitors, and the governmental authorities. The hotel industry is growing rapidly in developing countries due to the increase of the tourism industry; however, on the other hand, the hotel industry is one of the sectors which largely contribute to the environmental issues. Due to the huge number of environmental issues that hotel industry has encountered, carrying out sustainable business practices such as the adoption of GHRM bundle practices will provide a win-win situation for the organization and its stakeholders. To enhance environmental performance, GHRM bundle practices are important starting from recruitment and selection; training and development; 
Linking Green Human Resource Management Bundle to Environmental Performance in Malaysia's Hotel Industry: The Mediating Role of Organizational Citizenship Behaviour Towards Environment

performance appraisal; compensation and employee development. However, investment in GHRM bundle practices will have not only a direct effect on environmental performance, but also an indirect effect through several mediating variables because of the nature underlying the green HRM practices concept (Paillé, Boiral \& Chen, 2013). This result implies that the link between green HRM practices and environmental performance will be mediated by some other variables (Lin, Chang, \& Dang, 2015).

The success of environmental performance programs may hinge on employee behaviour ranging beyond the scope of formal reward and performance evaluation systems (Daily, Bishop and Govindarajulu, 2009). Environmental performance programs in organizations are regularly grounded on individual discretionary initiatives taken self-reliant of formal management structures (Paillé et al., 2013). The success of environmental performance programs and activities, consider the voluntary engagement and support from employees (Paillé et al., 2013). Therefore, employers need to take into account of discretionary behaviours (pro-environmental behaviours at work) that contribute to the environmental performance of the organization (Jackson \& Seo, 2010). Hotel industry literature has paid scarce attention to the identification of preceding organizational capabilities that could inspire the adoption of environmental performance programs, therefore, the analysis of organizational citizenship behaviour towards the environment (OCBE) as organizations' capability is more crucial, especially in Malaysian context as green adoption is still in the early stage (Moorthy, Yacob, Chelliah, \& Arokiasamy, 2012).

Based on the above arguments, this study argues that a hotel that invests in GHRM bundle practices will improve the OCBE of a hotel, which consequently increases its environmental performance. Hence, this study will determine how the green HRM practices through OCBE will help to enhance the environmental performance in Malaysia's hotel industry.

\section{LITERATURE REVIEW}

HRM practices are the actual human resource processes, programs, and techniques that executed in the organization or business unit (Arulrajah, Opatha, \& Nawaratne, 2016). In the same way, GHRM practices are the processes, programs, and techniques that get executed in the organization to diminish negative environmental effects or increase positive environmental effects of the organization (Arulrajah et al., 2016). Traditional HRM practices such as recruitment and selection, training and development, performance appraisal and compensation usually recognized as fundamental to the accomplishment of proactive environmental performance programs, however, HRM practices have to deliver the capabilities needed for the constant enhancement of the organizational environmental performance (Jabbour \& Santos, 2008) such as green recruitment and selection, green training and development, green performance appraisal and green compensation (Opatha \& Arulrajah, 2014). With regard to environmental performance programs in hotel industry such as waste reduction management, water management and conservation and energy management, all of these programs required behaviour change by employees (Harris \& Tregidga, 2012).

Investment in green HRM practices will have not only a direct effect on environmental performance, but also an indirect effect through several mediating variables because of the nature underlying the green HRM practices concept (Paillé et al., 2013). Green HRM is the business strategies that brings into line with the HR practices such as recruitment and selection, training and development, performance appraisal and compensation to an organization's environmental performance goals (Jackson, Renwick, Jabbour \& Muller-Camen, 2011). Daily, Bishop and Massoud (2012) found the positive relationship between green HRM practices and environmental performance in their study on 220 manufacturing organizations in Mexico. However, although HRM scholars pursue to recognize which HRM practices at the strategic or functional level can be selected to raise environmental performance, up to the present time, little consideration has been given to clarifying the individual process in which HRM practices generate the employees' readiness to adopt green behaviours at work, as when they shifting their environmental concerns of their private domain to the organizational domain, employees are more inclined to develop pro-environmental behaviour in the organization (Paillé et al., 2013).

According to Paillé et al. (2013), organizations can use suitable HRM practices such as recruitment and selection, training and development, performance appraisal and compensation to inspire their employees to accomplish environmental performance in an organization. Hence, several efforts have been made to discover what factors push employees to involve in the pro-environmental behaviours that support their organization to become environmentally concerned (Paillé et al., 2013). The green HRM practices such as training, performance appraisal, and compensation support to boost employees' motivation to validate the organization's environmental concerns, allowing it to be further competitive and to achieve environmental performance (Govindarajulu \& Daily, 2004).

The current study has acclaimed that employees' voluntary and discretionary environmental initiatives and behaviour must be considered as a critical aspect for organizations to attain environmental performance (Boiral \& Paillé, 2012; Daily et al., 2009). For that reason, employers must consider of discretionary behaviours that contribute to the environmental performance of the organization (Jackson \& Seo, 2010). Additionally, the study by Paillé et al. (2013) also recognized that voluntary and discretionary environmental behaviour such as OCBE fully mediates the relationship between strategic HRM practices (such as green HRM practices) and environmental performance.

Recruitment and selection activities involve the process of hiring individuals with environmental performance skills, knowledge, awareness and behaviours to achieve the 
organization's environmental performance (Jackson et al., 2011). Recruiting applicants with environmental and green awareness and environmental behaviours make it easy for organizations to induct experts who are alert with environmental performance programs, processes and methods and are already conversant with fundamentals like waste management and recycling (Ahmad \& Nisar, 2015). Consequently, the well-designed recruitment and selection activities may probably increase the employee's motivation to be involved in environmental performance programs and help them drive their OCBE that encourage the organization to turn into the green organization and lead to the environmental performance (Paillé et al., 2013). Furthermore, training and development activities play a critical role in the organization's environmental performance since training and development activities, execute a basic role to educate employees with new skills to accomplish tasks in environmental safety conditions that will influence the environmental performance of the organization (Cole, Elliott, \& Strobl, 2008). According to Daily et al. (2012), the knowledge andawareness supportt pave the approach for execution of effective environmental training programs and as the environmental performance programm is seen to be people oriented and expertise of employees are enhanced over training (del Brío, Fernandez, \& Junquera, 2007), therefore, this will lead to OCBE and environmental performance in the organization (Paillé et al., 2013).

On the other hand, a study by Govindrajulu and Daily (2004) propose that organizations must provide the feedback on the employees' efforts for the enhancement of the environment and the feedback may be available for employees if the organization has a proper performance appraisal procedure. Chinander (2001) also highlighted that performance appraisal of the employee's guarantees that the employees are aware of their responsibilities and such awareness leads to enhanced environmental performance. Hence, to retain the employees motivated towards the organization's environmental performance, it is critical that the approach of the employees' performance be evaluated (Jabbar \& Abid, 2014). Therefore, the well-designed performance appraisal procedures may boost the employees to be involved in environmental performance programs and help them drive their OCBE that support the organization to turn into the green organization and at the end of the day will lead to the environmental performance (Paillé et al., 2013).

Compensation system plays a critical role in encouraging the employees and support in recognizing their performance in job towards environmental performance and organizations using compensation to motivate, accomplish and retain employees for accomplishing and understanding the importance of environmental performance in the organizations (Jabbar \& Abid, 2014). The use of environmental compensation (monetary and non-monetary) has shown that they have a significant impact on employee motivation to participate in environmental performance programs (Renwick, Redman \& Maguire, 2013). Therefore, the well-designed compensation system could encourage the employees to be involved in environmental performance programs and help the employers to push their employees to involve in the OCBE that support their organization to become more environmentally concerned and at the end of the day will lead to the environmental performance (Paillé et al., 2013).

OCBE is represented by RBV Theory as Barney (1991) established one of the major resources that contribute to the organization's competitive advantage that is the organizational resources and capabilities that diverse and immobile such as OCBE because OCBE is acting to as a motivating approach to capturing pro-environmental behaviours in the organization, and these behaviours are irreplaceable due to the diverse capabilities of individuals to contribute efficiently to environmental action (Paillé et al., 2013).

Therefore, this study conjectures that OCBE mediates the relationship between GHRM bundle practices (green recruitment and selection; green training and development; green performance appraisal; and green compensation) and environmental performance.

\section{METHODOLOGY}

\section{Sample and Data Collection}

To test our hypotheses, we collected data from 206 hotels in Malaysia. The total number of hotels registered in Malaysia is 2,091 hotels (Ministry of Tourism and Culture Malaysia, n.d). The target population of this study comprises 3-, 4- and 5-star hotels and respondents were the HR managers in these registered hotels as stated in the Ministry of Tourism and Culture Malaysia. The total number of 3-, 4and 5-star hotels registered in Malaysia is 721 hotels (April 2016) based on the statistics provided by Ministry of Tourism and Culture Malaysia as stated in Table 1. A total of 250 questionnaires were distributed to target respondents. Of these 250 questionnaires distributed, a total of 225 questionnaires were returned. Among these, only 19 returned questionnaires were unusable due to incomplete information. The final usable questionnaires were 206 which accounted for 82 per cent response rate.

Table 1. Total Number of Hotel in Malaysia Based on Star Type of Hotel Number of Hotel

\begin{tabular}{ll}
\hline 3-star & 475 hotels (65.88 percent) \\
$\begin{array}{l}\text { 4-star } \\
\text { 5-star }\end{array}$ & 99 hotels (20.39 percent) \\
$\begin{array}{l}\text { Total Number of } 3,4 \text { and } 5 \text {-star } \\
\text { hotels in Malaysia } \\
\text { up to April } 2016 .\end{array}$ & 721 hotels \\
\hline
\end{tabular}

Source: Prepared by the author.

Measurement 
Linking Green Human Resource Management Bundle to Environmental Performance in Malaysia's Hotel Industry: The Mediating Role of Organizational Citizenship Behaviour Towards Environment

A combination of existing validated measurements, extensive literature review (items as conceptualized by the author) and with the help of academic and industry experts were utilized to develop an instrument for this research. At the initial stage, this research used an existing validated measurement to measure all variables in this study. This research conducted an in-depth pilot interview with three HR managers of the hotel in Malaysia and asked two academic HR management experts to review the questionnaires. The researcher asked them to specify any ambiguity about the phrasing of the items. Based on the feedback, the HR Managers provided suggestions to add more items to measure independent variables, green HRM practices as the initial items adapted from Jabbour, Santos, and Nagano (2010) are difficult for them to understand further. Therefore, this study added items as conceptualized by Arulrajah et al. (2016) to make the questions clearer and more understandable. For the mediator variable; OCBE, the measurement has developed from the study by Boiral, Talbot, and Paille (2013).

Furthermore, this research was designed for items designated as independent variables with environmental performance based on the actual practices in Malaysia's hotel industry. The actual practices of environmental performance in Malaysia's hotel industry were adapted from a qualitative study by Yusof and Jamaludin (2013). As these items are conceptualized items and are not statistically tested, to ensure content validity, therefore, the reliability of the items was measured using Cronbach alpha.

\section{Green Human Resource Management Bundle Practices}

In this study, GHRM bundle practices comprises four components which are; green recruitment and selection, green training and development, green performance appraisal and green compensation. This study adapted the questions from Jabbour et al. (2010) and Arulrajah et al. (2016). Furthermore, this study used the 5-point Likert Scale ( 1 = strongly disagree, 5 = strongly agree $)$.

Organizational Citizenship Behaviour towards Environment

The mediator variable for this study is OCBE. The measurement for OCBE has developed from Boiral et al. (2013). Each dimension of OCBE was measured on a 5-point Likert scale, ranging from one (strongly disagree) to five (strongly agree). This study adapted 3-items in the study by Boiral et al. (2013) to confirm that OCBE is the mediator variable on the relationship between GHRM bundle practices and environmental performance in Malaysia's hotel industry.

\section{Environmental Performance}

To measure environmental performance, Yusof and Jamaludin's scale (2013) was employed. These items were tested as a qualitative measurement. The Cronbach's alpha reported for the overall items from this study is 0.817 . Each dimension of environmental performance was measured on a 5-point Likert scale, ranging from one (strongly disagree) to five (strongly agree).

\section{ANALYSIS}

\section{Measurement Model}

This study used the two-step approach as suggested by Anderson and Gerbing (1988). Firstly, the study assessed convergent validity and reliability and the discriminant validity. Convergent validity can be ascertained if the loadings are greater than 0.5 (Hair, Black, Babin, \& Anderson, 2010), composite reliability greater than 0.7 (Gefen, Straub, \& Boudreau, 2000) and the average variance extracted is greater than 0.5 (Fornell \& Larcker, 1981) as stated in Table 2. This study also tested for the discriminant validity using the evaluation of the heterotrait-monotrait ratio of correlations (HTMT) (Henseler, Ringle, \& Sarstedt, 2015). Using HTMT as a criterion to access discriminant validity, the researcher needs to compare it to a predefined threshold. Hence, if the value of the HTMT is greater than its predefined threshold, the researcher can conclude that there is a nonexistence of discriminant validity. This study used a conservative threshold of 0.85 as suggested by Clark and Watson (1995) and Kline (2015) as stated in Table 3.

Table 2. Results of Measurement Model

\begin{tabular}{ccccc}
\hline $\begin{array}{c}\text { Model } \\
\text { Constructs }\end{array}$ & $\begin{array}{c}\text { Measurement } \\
\text { Items }\end{array}$ & Loadings & AVE & CR \\
\hline $\begin{array}{c}\text { GHRM } \\
\text { Bundle }\end{array}$ & GC1 & 0.785 & 0.509 & 0.949 \\
& GC2 & 0.783 & & \\
& GC3 & 0.778 & & \\
& GC4 & 0.774 & \\
& GPA1 & 0.796 & \\
& GPA2 & 0.807 & \\
& GPA3 & 0.817 & \\
& GPA4 & 0.824 & \\
& GRS1 & 0.614 & \\
& GRS2 & 0.611 & \\
& GTD1 & 0.678
\end{tabular}

Source: Prepared by the author.

Table 3. Discriminant Validity of Constructs

GHRM Bundle $\quad$ EP OCBE

\section{GHRM Bundle}

EP

0.395 
Source: Prepared by the author.

\section{Structural Model}

The structural model was tested next. The results are presented in Table 4 . The $\mathrm{R} 2$ is 0.044 meaning that 4.4 per cent of the variance in environmental performance was explained by the GHRM bundle practices through OCBE. Bootstrapping of 5,000 resamples was conducted to determine the path coefficient values and the $t$ values for the path. Therefore, looking at structural path, GHRM bundle practices $(\beta=0.073, \mathrm{p}<0.10)$, have a significant indirect effect on environmental performance, through organizational citizenship behaviour towards the environment as the mediator.

Table 4. Summary of Path Coefficient

\begin{tabular}{llllll}
\hline & Beta & Standard & T-statistic & p-Value & Decision \\
& & Error & & & \\
\hline GHRM & 0.073 & 0.022 & $2.811^{*}$ & 0.005 & Supported \\
Bundle ->EP & & & & & \\
\hline
\end{tabular}

Source: Prepared by the author.

Notes: * $p=1$ per cent (based on one tail test with 5,000 bootstrapping).

\section{DISCUSSION}

The major finding from this study is GHRM bundle practices have a significant indirect effect on environmental performance, through organizational citizenship behaviour towards the environment as the mediator. In Malaysia, green adoption is still in the early stage (Moorthy et al., 2012), and green HRM practices still at emerging stage in Malaysia and gain minor attention (Aragon-Correa, Martin-Tapia, \& de la Torre-Ruiz, 2015). Therefore, the analysis of OCBE as organizations' capability is more crucial and the results show that only 4.4 per cent of the variance in environmental performance was explained by the GHRM bundle practices through OCBE. As green HRM practices still at emerging stage in Malaysia, employees might not get much information about these practices and this situation will not lead to voluntary actions. However, the results from this study shows that GHRM bundle practices (green recruitment and selection; green training and development; green performance appraisal; and green compensation) lead to the informal voluntary initiatives taken independenly by the employees out of the participation based on compliance with the formal rules and standards.

\section{CONCLUSION}

From the aforementioned discussion, it can be concluded that GHRM bundle practices (green recruitment and selection; green training and development and green compensation) have lead to organizational citizenship behaviour towards environment and help to enhance the environmental performance in the hotel industry. In addition, OCBE has rarely been empirically observed in the literature on environmental performance and management (Ramus \& Killmer, 2007). Many environmental performance and management studies do not differentiate between employees' voluntary participation and participation based on compliance with the organization's internal procedures and standards (Boiral, 2009 ; Ramus \& Killmer, 2007). Hence, this study gives new perspective on the strategic sustainable concept which organizations can implement the GHRM bundle practices in order to gain competitive advantage towards the environmental performance.

\section{REFERENCES}

1. Ahmad, S., \& Nisar, T. (2015). Green Human Resource Management: Policies and practices.

2. Cogent Business \& Management, 2(1), 1030817.

3. Alfes, K., Shantz, A. D., Truss, C., \& Soane, E. C. (2013). The link between perceived human resource management practices, engagement and employee behaviour: a moderated mediation model. The international journal of human resource management, 24(2), 330-351.

4. Anderson, J. C., \& Gerbing, D. W. (1988). Structural equation modeling in practice: A review and recommended two-step approach. Psychological bulletin, 103(3), 411.

5. Aragon-Correa, J. A., Martin-Tapia, I., \& de la Torre-Ruiz, J. (2015). Sustainability issues and hospitality and tourism firms' strategies: Analytical review and future directions. International Journal of Contemporary Hospitality Management, 27(3), 498-522.

6. Arulrajah, A. A., Opatha, H. H. D. N. P., \& Nawaratne, N. N. J. (2016). Green human resource management practices: a review. Sri Lankan Journal of Human Resource Management, 5(1).

7. Barney, J. (1991). Firm resources and sustained competitive advantage. Journal of Management, 17(1), 99-120.

8. Boiral, O. (2009). Greening the corporation through organizational citizenship behaviours. Journal of Business Ethics, 87(2), 221-236.

9. Boiral, O., \& Paillé, P. (2012). Organizational citizenship behaviour for the environment:

10. Measurement and validation. Journal of Business Ethics, 109(4), 431-445

11. Boiral, O., Talbot, D., \& Paillé, P. (2015). Leading by example: A model of organizational citizenship behaviour for the environment. Business Strategy and the Environment, 24(6), 532-550.

12. Brammer, S., Millington, A., \& Rayton, B. (2007). The contribution of corporate social responsibility to organizational commitment. The International Journal of Human Resource Management, 18(10), 1701-1719.

13. Chinander, K. R. (2001). Aligning accountability and awareness for environmental performance in operations. Production and Operations Management, 10(3), 276-291.

14. Clark, L. A., \& Watson, D. (1995). Constructing validity: Basic issues in objective scale development. Psychological Assessment, 7(3), 309.

15. Cole, M. A., Elliott, R. J., \& Strobl, E. (2008). The environmental performance of firms: The role of foreign ownership, training, and experience. Ecological Economics, 65(3), 538-546.

16. Cole, M. A., Elliott, R. J., \& Strobl, E. (2008). The environmental performance of firms: The role of foreign ownership, training, and experience. Ecological Economics, 65(3), 538-546.

17. Combs, J., Liu, Y., Hall, A., \& Ketchen, D. (2006). How much do high-performance work practices matter? A meta-analysis of their effects on organizational performance. Personnel psychology, 59(3), 501-528.

18. Daily, B. F., Bishop, J. W., \& Govindarajulu, N. (2009). A conceptual model for organizational citizenship behaviour directed towards the environment. Business \& Society, 48(2), 243-256.

19. Daily, B. F., Bishop, J. W., \& Massoud, J. A. (2012). The role of training and empowerment in environmental performance: A study of the Mexican maquiladora industry. International Journal of Operations \& Production Management, 32(5), 631-647.

20. del Brío, J. Á., Fernandez, E., \& Junquera, B. (2007). Management and employee involvement in 
Linking Green Human Resource Management Bundle to Environmental Performance in Malaysia's Hotel Industry: The Mediating Role of Organizational Citizenship Behaviour Towards Environment

achieving an environmental action-based competitive advantage: an empirical study. The International Journal of Human Resource Management, 18(4), 491-522.

21. Dutta. S. (2012). Greening people: a strategic dimension. ZENITH International Journal of Business Economics \& Management Research, 2(2), 143-148.

22. Fornell, C., \& Larcker, D. F. (1981). Evaluating structural equation models with unobservable variables and measurement error. Journal of Marketing Research, 39-50.

23. Gefen, D., Straub, D., \& Boudreau, M. C. (2000). Structural equation modeling and regression: Guidelines for research practice. Communications of the association for information systems, 4(1), 7.

24. Govindarajulu, N., \& Daily, B. F. (2004). Motivating employees for environmental improvement. Industrial Management \& Data Systems, 104(4), 364-372.

25. Hair, J. F., Black, W. C., Babin, B. J., \& Anderson, R. E. (2010). Multivariate Data Analysis. Vectors.

26. Harris, C., \& Tregidga, H. (2012). HR managers and environmental sustainability: strategic leaders or passive observers?. The International Journal of Human Resource Management, 23(2), 236-254.

27. Henseler, J., Ringle, C. M., \& Sarstedt, M. (2015). A new criterion for assessing discriminant validity in variance-based structural equation modeling. Journal of the Academy of Marketing Science, 43(1), 115-135.

28. Jabbar, M. H., \& Abid, M. (2014). GHRM: Motivating Employees towards Organizational Environmental Performance. Magnt. Res. Rep., 2, 267-278.

29. Jabbour, C. J. C., \& Santos, F. C. A. (2008). The central role of human resource management in the search for sustainable organizations. The International Journal of Human Resource Management, 19(12), 2133-2154.

30. Jabbour, C. J. C., Santos, F. C. A., \& Nagano, M. S. (2010). Contributions of HRM throughout the stages of environmental management: methodological triangulation applied to companies in Brazil. The International Journal of Human Resource Management, 21(7), 1049-1089.

31. Jackson, S. E., Renwick, D. W., Jabbour, C. J., \& Muller-Camen, M. (2011). State-of-the-art and future directions for green human resource management: Introduction to the special issue. German Journal of Human Resource Management, 25(2), 99-116.

32. Jackson, S. E., \& Seo, J. (2010). The greening of strategic HRM scholarship. Organization Management Journal, 7(4), 278-290.

33. Kline, R. B. (2015). Principles and practice of structural equation modeling. Guilford publications.

34. Lin, C. S., Chang, R. Y., \& Dang, V. T. (2015). An integrated model to explain how corporate social responsibility affects corporate financial performance. Sustainability, 7(7), 8292-8311.

35. Ministry of Tourism and Culture Malaysia. (n.d.). Retrieved July, 2015 and October, 2017, from www.motac.gov.my/en/

36. Moorthy, M. K., Yacob, P., Chelliah, M. K., \& Arokiasamy, L. (2012). Drivers for Malaysian SMEs to Go Green. International Journal of Academic Research in Business and Social Science, 2(9), 74-86.

37. Opatha, H. H. D. N. P., \& Arulrajah, A. A. (2014). Green human resource management:

38. Simplified general reflections. International Business Research, 7(8), 101.

39. Paillé, P., Boiral, O., \& Chen, Y. (2013). Linking environmental management practices and organizational citizenship behaviour for the environment: a social exchange perspective. The International Journal of Human Resource Management, 24(18), 3552-3575.

40. Ramus, C. A., \& Killmer, A. B. (2007). Corporate greening through prosocial extrarole behaviours-a conceptual framework for employee motivation. Business Strategy and the Environment, 16(8), 554-570.

41. Renwick, D. W., Redman, T., \& Maguire, S. (2013). Green human resource management: A review and research agenda. International Journal of Management Reviews, 15(1), 1-14.

42. Yusof, Z. B., \& Jamaludin, M. (2013). Green approaches of Malaysian green hotels and resorts. Procedia-Social and Behavioural Sciences, 85, 421-431.

43. Zientara, P., \& Zamojska, A. (2016). Green organizational climates and employee pro-environmental behaviour in the hotel industry. Journal of Sustainable Tourism, 1-18. 